\title{
Quantitative Film Radiography
}

\author{
G. Devine, D. Dobie, J. Fugina, \\ J. Hernandez, C. Logan, P. Mohr, \\ R. Moss, B. Schumacher, E. Updike, D. Weirup
}

February 26, 1991

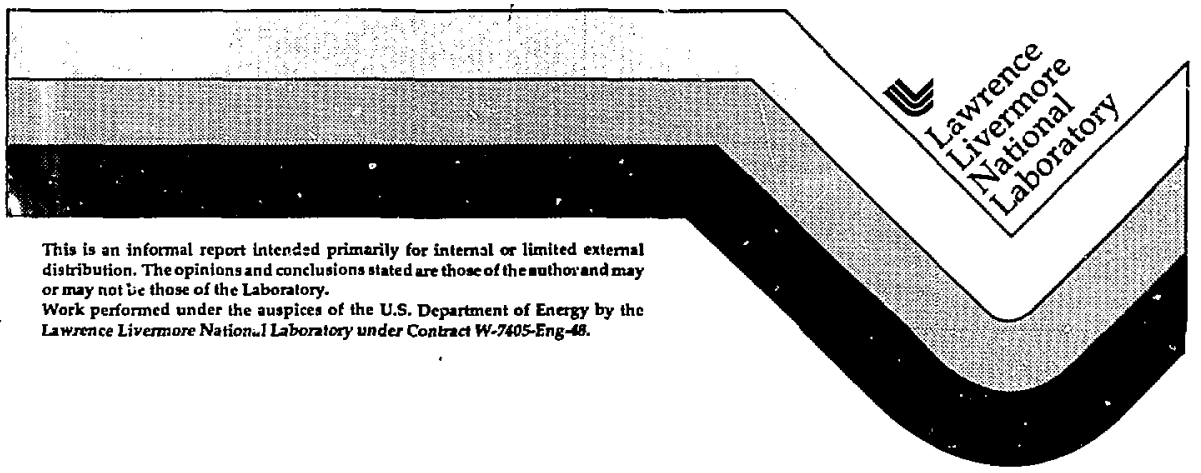


This report presents slightly expanded versions of summaries of four papers to be presented to the Spring 1991 ASNT Conference in Oakland, California. These four presentations describe a system of quantitative radiography developed at LLNL. ASNT limits the lengths of summaries they publish and prohibits the use of color. Since both limitations impede description of our work, we elected to produce this report and to have it available for distribution at the ASNT Conference. Figures and tables are nurnbered sequentially within each section.

It is not practical to include all of the authors of this work on the ccver. The authors of the four ASNT presentations are shown below in bold print. The system described in this repor has been developed over seven years and required many man-years of effort. Obviously it represents the efforts of many people. They are: Pete Abelar, Laura Aitclison, Bob Alexander, Sharon Alvarez, Steve Azevedo, Brian Baker, Larry Barr, Jim Brase, Eileen Bryson, Will Burden, Steve Caldwell, Gus Carlson, John Celeste, Carol Chapinan, Laura Colberg, Chuck Cook II, Ricky Copobianco Gary Devine, Claude Dittmore, Doug Dobie, John Duncan, Phil Durhin, Doug Ebersole, Bob Ellers, George Ellliot, Jim Fischer, Gene Ford, Hans Frick, Bill Fritts, Jim Fugina, Mark Gabel, Pat Gennaro, Dan Gilmore, George Govemo, Darryl Griffin, Dave Gutierтez, Phil Hahn, Larry Hall, Jerry Haskins, Beryl Held, Joe Hendrix, Jose M. Hernandez, Steve Homann, Randy Hurd, Ziggy Jandrisevits, Walt Kendricks, Jim Kervin, John Kinney, Gordon Krauter, Satish Kulkarni, Bob Lemon, Dan Lewis, Clint Logan, Sharlene Lundin, Hirry Martz, Warren Massey, Dale Mauldin, Pete Mohr, Ray Moss, Dave Neal, Candy Nelson, Dzung Nguyen, Mike Niblack, Margo Nichols, Jeff Oh, Mike Ong, John Poco, Derrill Rikard, Pat Roberson, Marty Roeben, Scott Ruddell, Dick Ryon, Alan Saroyan, Dan Schne'erk, Bruce Schumacher, Jim Sedlacek, Dennis Silva, Mike Skeate, Ken Skinnell, Steve Smith, Diane Spaulding, June Stewart, Ron Streit, Tom Takemori, Earl Updike, Larry Valby, Chuck Valente, Jerry Vattone, Ken Waltjen, Alan Wardlow, Rolly Watson, Linda Weekes, Dave Weirup, Cookje West: Mel Wieting, Bill Wilcox, Susan Winfree, Steve Wolfe, Eric Ziebarth. Harry Galles possessed the leadership and vision to recognize the need and to obtain the resources.

\title{
DISCLALMER
}

\begin{abstract}
This repon was prepared as an account of work sponsored by an agency of the United States Government. Neither the United States Government nor any agency thereof, nor any of their employees, makes any warranly, express or implied, or assumes any legal liability or responsibility for the aecuracy, compleientess, of yselulness of any information, apparatus, produch or process disclosed, or represents that its use would not infringe privately owned tights. Reference herein to any specific commercial product, process, or service by trade name, trademark. manufacturer, or otherwise does wol necessarily conslitute or imply its endorsement, rocommendation. or favoring by the United States Government or any agency theseof. The vieus and opinions of authors expressed herein do nol necessarily state of reflect those of the United States Goternment or any agency the reof.
\end{abstract}


Table of Contents

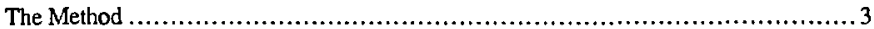

Film Processor Monitoring and Controi........................................ 8

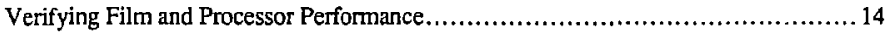

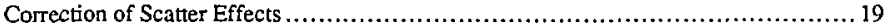

References................................................................... 26 


\section{Quantitative Film Radiography}

\section{The Method}

We have developed a system of quantitative radiography in order to produce quantitative images displaying homogeneity of parts. The materials that we characterize are synthetic composites and may contain important subtle density variations not discernable by examining a raw film $x$-radiograph. In order to quantitatively interpret film radiographs, it is necessary to digitize, interpret, and display the images. Our integrated system of quantitative radiography displays accurate, high-resolution pseudo-color images in units of densiry. We characterize approximately 10,000 parts per year in hundreds of different configurations and compositions with this system.

Images are captured using DuPont NDT55 industrial x-ray film in Daypack packages. $X$-ray cabinets are of custom design, with helium flight path and a filter wheel for positioning filters if desired. The cabinets contain baffles to reduce scattered radiation and are equipped with drawers for rapid load/unload of parts. Separate units with tungstenanode or copper-anode tubes are available. The usual operating voltage is 15 to $35 \mathrm{kVp}$. Fixturing provides for rough part positioning and precise alignment with respect to the $x$-ray source.

Areal density standurds are placed at several locations on each film. In interpreting the image, we use the standards newrest the image of the part being qu. $\cdots$ ufied. Because of this, small variations in $x$-ray flux uniformity (heel effects) are unimportant. The usual standard is a step wedge of aluminum containing 13 steps. Films are permanently labelled by imaging a perforated metal numbering strip. Data such as part number, step wedge identification, etc. are read from barcode labels and transferred to a data base for later retrieval and use in quantifying the image.

Before beginning production runs of a particular material and configuration, we establish the radiographic conditions to be used. We then determine the "equivalence" between the aluminum standard and the miterial of interest. Let the material to be characterized be represented by $\mathrm{Un}_{\mathrm{n}}$ and the aluminum standard by Al. Equivalence simply means that, on a film radiograph, for any specified areal density (mass/area) of Un, these existr some vaiue of areal density of Al that produces the same film density. This is depicted in Figure 1. We wish to discover a functional form for the relationship between the areal density of Al, $(\rho t)_{A l}$, and the areal density of $U n,(\rho t)_{U n}$, for equal film density. We have found that the experimental data is very well represented by a fit of the functional form

$$
\left.(\rho t)_{U n}=a\left[(\rho t)_{A}\right]\right]^{b}
$$

equation \#1

The equivalence then, is represented by the two coefficients, $a \& b$. The values of a \& $b$ are especially sensitive to the $x$-ray spectrum used for the exposure, and consequently to the $\mathrm{x}$-ray tube, $\mathrm{kV}_{\mathrm{p}}$, flight path distance, flight path composition, and filtering.

Film processing must be carefully controlled, and a system must be established to monitor film and processor performance. Later sections address the systems we have developed. 
Our main production digitizer is made by DuPont. The DuPont digitizer utilizes an adjustable halogen light source. The film is translated over a 17-inch range. The light source and a 14-inch long (linear) CCD detector array are stationary. Pixel size is fixed at $70 \mu \mathrm{m}$. For convenience, the 12 bit output from the CCD array is converted to film density by interpolating calibration curves that are derived from digitizing an NBS film density standard. The accuracy of the calibration to NBS film density is unimporant to the final result. This is true because the image is interpreted in terms of the comparison to a reference standard in the image.

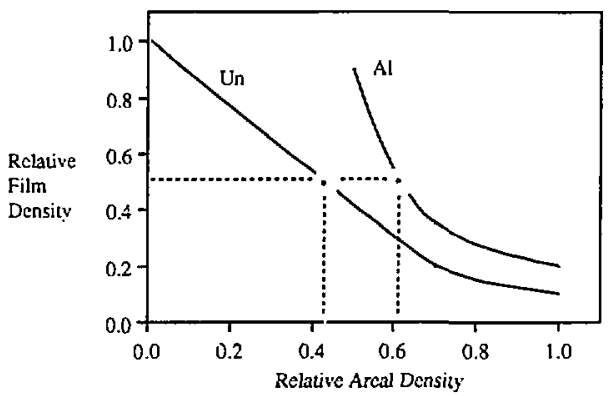

Figure 1. Schematic plot of relationship between film density and areal density of $\mathrm{Al}$ and Un.

We digitize a full $7 \times 17$ inch film. The first analysis step is to identify the part locations and boundaries. This is done by segmentation software. Fixturing used during image formation restricts the location of part images to specific regions called "slots". The Al step wedge locations are located by the software by keying from fiducials in the image. Using the film and slot number, the analysis software accesses the data base to obtain all the data needed to interpret the image of each part.

We determine the average film density of a 15-pixel-square array near the center of each step on each Al step wedge. The Al step wedge identification number from the data base leads to a table of areal density values for each Al step wedge step. We disregard those steps with density less than 1.8 or more than 3.0 . We fit a third-order polynonial to this data of the form

$$
\mathrm{FD}=\mathrm{c}_{1}+\mathrm{c}_{2}(\rho \mathrm{t})_{\mathrm{Al}}+\mathrm{c}_{3}\left[(\rho \mathrm{t})_{\mathrm{Al}}\right]^{2}+\mathrm{c}_{4}\left[(\rho \mathrm{t})_{\mathrm{Al}}\right]^{3}
$$
equation \#2

where FD is film density and $c_{1}$ through $c_{4}$ are coefficients determined by the fitting process.

The $x$-ray unit identification, part number, step wedge identification, and radiographic conditions previously read from the data base are used to retrieve appropriate values of the coefficients $9 \&$ b from look-up tables. 
So, for each pixel, we use the measured film density to solve for the real root of equation $\# 2$, thus determining the areal density of $\mathrm{Al},(\rho \mathrm{t})_{\mathrm{Al}}$, that would result in the film density observed for the pixel in question. We then use equation $\# 1$ to calculate $(\rho t)$ Un for that pixel. In order to display the data in actual density units (mass/volume), the actual measured thickness for each part (from the data base) is divided into the areal density. (In our case, the thickness is uniform for each part. It would however be an easy matter to use know part configuration to account for the effect of a variable thickness.) This resulting image is stored in a digital file accessible to the engineer responsibie for part acceptance.

One measure of the performance of quantitative radiography is the agreement achieved with other measurement methods. Figure 2 compares the average value of density derived from quantitative radiography with an independent $x$-ray gaging measurement of 84 similar parts. The average difference is $<0.1 \%$ wilh a standard deviation of $1.24 \%$. Similar agreement is achieved between quantitative radiography and destructive ana'ysis methods.

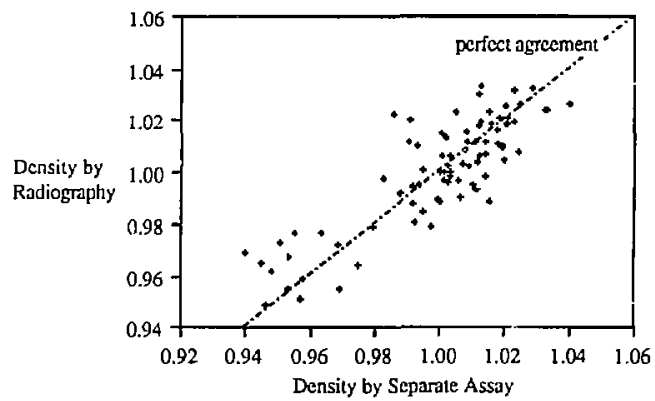

Figure 2. Agreement between average density determined by quantitative radiography and density determined by a separate method.

We also derive various integral characteristics of the image, and therefore of each part. Two important measures of density uniformity are the relative standard deviation of the image pixels within the part and the "Kervin Factor". The Kervin Factor is a measure of the average distance one must move within the image before encountering a 5\% density variation in a single pixel. This factor closely corresponds to "graininess" as perceived by human interpreters. Contrast in the original film imige $\left[\Delta(F D) \div \Delta(\rho t)_{U n}\right.$ at the mean value of $\left.(\mathrm{pt})_{\mathrm{U}}\right]$ is also derived and checked against software limits for acceptability.

In some cases, radiographic conditions cannot be arranged so that scattered radiation (into or out of the image of a part) is negligible. In these cases a scatter correction, described later, is made. 
The use of color display is central to quantitative display of images. We have selected a color bar such that the average densiry of the par is displayed as green. Thus a perfectly homogeneous part is perfectly green. The user selects the range of data to be displayed, for example from $-10 \%$ to $+10 \%$ of the average. The quantitative images (two views) are displayed on color monitors. Hard copy is made only for show-and-tell.

Figures 4 \& 5 present quantitative images of typical parts. Integral measures of the homogeneity of these two parts are presented in Tables $1 \& 2$.

Table 1. Integral Homogeneity Properies of Zero Deqree Images of Figs. $4 \& 5$.

\begin{tabular}{|c|c|c|}
\hline Part & $\begin{array}{l}\text { 0-'Kervin } \\
\text { Factor* } \\
\text { (pixels) }\end{array}$ & $\begin{array}{l}0^{\circ} \\
\text { Std Dev. } \\
(\%)\end{array}$ \\
\hline $\begin{array}{l}\text { HGSXS001DA } \\
\text { HGSXS024DA }\end{array}$ & $\begin{array}{l}40.8 \\
43.6\end{array}$ & $\begin{array}{l}1.09 \\
1.01\end{array}$ \\
\hline
\end{tabular}

* The Kervin Factor is the average number of $70 \mu \mathrm{m}$ pixels one can move within the image before encountering a pixel more than $5 \%$ different from the starting pixel.

Table 2. Integral Homogeneity Properties of Ninery Degree Images of Figs. 4\&:5.

\begin{tabular}{|c|c|c|}
\hline Part & $\begin{array}{l}90-\text {-Kervin } \\
\text { Factor* } \\
\text { (pixels) }\end{array}$ & $\begin{array}{l}90^{\circ} \\
\text { Std Dev. } \\
(\%)\end{array}$ \\
\hline $\begin{array}{l}\text { HGSXSO01DA } \\
\text { HGSXS024DA }\end{array}$ & $\begin{array}{l}34.5 \\
42.3\end{array}$ & $\begin{array}{l}1.68 \\
0.94\end{array}$ \\
\hline
\end{tabular}

* The Kervin Factor is the average number of $70 \mu \mathrm{m}$ pixels one can move within the image before encountering a pixcl more than $5 \%$ different from the starting pixel. 
HGSXSOOIDA: DO DEGREE TOP OR LEFT VEW

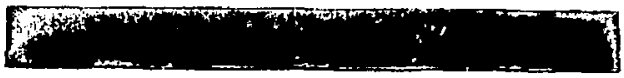

HGSXSOOIDA: O DEGAEE VEW
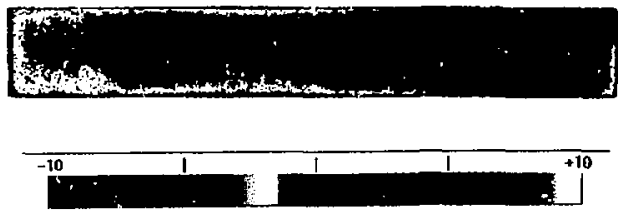

Figure 4. Quantitative part image. This part is of lesser homogeneity than the part shown in Figure 5. It also contains a gradual density gradient from the lower left to upper right in the sero-degree view that is not observabie by unaided numan interpreters

HGSXSO24DA: DO DECIEE TOP OR LEFT VEW

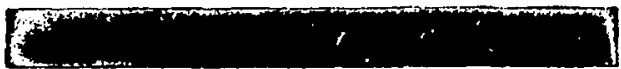

HGSXSOZYDA: O DEGREE VIEW
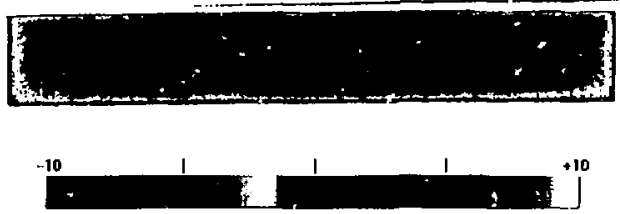

Figure 5. Quantitative part image. This part is of greater homogeneity than the par shown in Figure 4. 


\section{Intraduction - The Stability of Chemical Film Processing}

The development or image forming step is just one of the essential steps in creating an $\mathbf{x}$ ray film record. (Ref. 1) There are a number of possible procedures for accomplishing this step. The most common are hand development in open tanks and mechanized (automatic transport) processing in a purpose built machine. Most curent processing of x-ray films is probably done by such processing machines. One of the characteristics of any film processing procedure is the issue of reuse and/or replenishment of working solutions. Not only are some of the components of tie development chemistry consumed or modiñied in the image forming process but also, elements of the film image and emulsion structure may be rejected in to the developing solution. With the exception of single use, e.g. gel chemistry or "throw away" techniques, film processing is inevitably done in solutions contaminated with the waste of prior use. This introduces the issue of progressive change in the background chemistry in which the image formation process takes place. In hand development, solutions may be used until some acceptable limit of degradation is reached and then discarded or "replenished", either with complete or selected chemistry, usually in stepwise fashion for extended use. Most automated film processors are equipped for incremental teplenisliment with varying degrees of sophistication as to contol of the amount and timing of intoduction. In most such systems, overflow of the working solucion occurs as a result of initroduction of the replenisher to keep within system volume limits. The result is an asymptotic approach to an equilibrium level of contamination of the working chemistry.

\section{Equilibrium Contamination of Working Developer Solutions}

Front the standpoint of chernical activity, the most significant contaninant in used developer is bromine, usually a potassium-bromide which is released in substantial quantity from the silver-bromide of the emulsion. The concentration levels of bromine in developer increase from st:bstantially nil for fresh developer solution to whatever limiting levels are tolerable for acceptable image formation. (Ref.2) The present commercial practice for the most commonly used developers is to replenish to equilibrium levels of bromine of the order 8 to 12 grams bromine per liter (or 1.5 times these numerical values when expressed as potassium-bromide). Because this would represent a substantial and extended ransient in chemistry cn initial startup of new solution, it is common practice to "pre-contaminate" the beginning ("fresh") developer solution with bromine to about half the equilibrium level by adding concentrated bromine in the form of a "starter" solution. Since even this results in a substantial period of transient chemistry, it is common to recommend processing of a number of blank (exposed) films to furthc: "condition" - i.e. increase the contamination toward the equilibrium level which will be reached with programmed replenishment. This approach to equilibriuni may exiend through 50 or more flims.

\section{Experience with Automated Film Processing at LLNL}

At Lawrence Livermore National Laboratory, we operate a number of automated film processors at both fixed and field locations in support of $x$-ray NDE. Some time ago, one of our programmatic custoners with interest in precision x-ray densitometry for materials characterization approached us with evidence of ume wise variability in the image forming perfornance of our $\mathrm{x}$-ray film processors. The degree of variability implied, based on 
precision $x$-ray dosimetry and film densitometry, ranged as high as 12 or 13 percent. We were asked to consider the feasibility of reducing this variability to the order of 1 percent Review of the problem took into consideration the usual range of variables including source, exposure, film, processing and storage. We knew that many of these: other considerations included potential uncertainties greater than the 1 percent goal but decided to address variability in the image forming contribution alone. In an attempt to increase the understanding of and place some bound on the variability of the image forming step, it was decided to measure, record and hopefully control eleven yariables associated with the processing procedure. These included temperatures, flow and transpori rates and chemical activity represented by continuous in-line pH monitoring and periodically sampled bromine ion concentration by titration chemistry analysis.

We quickly learned the problems and limits associated with precise control of processor variables. In modern film processors, most of the variables, except for those which are chemisty rolated, proved to be tractable if not trouble free. We routinely produced written records of the variables to accompany the processing of any piece of film. The most important thing we learned in the early stages was that we had been working against our own interests in maintenance practices which increased the variability of the developer chemistry by too frequent solution replacement and arbitrary (often over generous) replenishment. The weak link in what had become an otherwise very valuable and useful aid to maintaining processing uniformity was the non-continuous bromine analysis.

Economic considerations limited the frequency of analysis to twice a week and then once a week which is too infrequent for anything approaching "real time" control. (Figure1) Consultation with both process and analytic chemists led us to foc us on $x$-ray iluorescence as the most promising candidate for on-line approach to analysis.

bromine concentration (g/iwer)

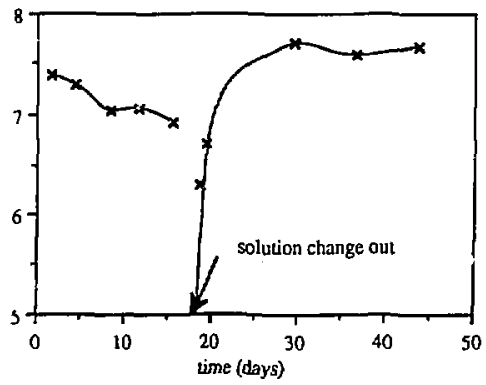

Figure 1. Time dependence of bromine concentration in developer from chemical analysis of samples. 


\section{Evolution, Design, and Description of a Computer Manitored Processor}

Our facility maintenance plan provides for periodic replacement of equipment such a: processors when their economic lifetime is exceeded. In this instance the advanced age of the highest production processor, on which most of the development of precision (inaterial) densitometry films were processed, presented the opportunity to create a monitored system operating under computer control within an existing (MacIntosh-based) reporting and recording network. The system which evolved resulted from considcration of requirements from many points of view.

The newest generaticn of our computer monitored processor was designed with the idea of expandability and ease of modifications in mind. The system (see Figure. 2 simplified block diagrami) was developed around a Macintosh IIX computer using LabVIEW 2 icon based programming platform. Reasons for choosing this system were to use the nerworking capability and expandability of the Mac, and the capability of running the software under multifinder. This allows the computer to be used for other applications while the processor monitoring program is running in the background, making the computer a nondedicated system. There was the need, as in our earlitr generation. processor monitoring system, for a visual meter readout panel above the film feed tray in the dark room. These panel meters provide several important functions. If there is a problem with any processor parameters it can be observed locally, (in addition to the remote compuier monitor display and print out in the Radiography office) and corrected before films are processed. The panel meters also provide the needed excitation and signal conditioning for the RTD temperature probes, $\mathrm{pH}$ probes, optical encoder, and flow sensor. The analog output signals from the meters are wired differentially to the V/O connector blocks analog input channels which connect the signals to the computers multifunction (A/D, D/A,I/O) interface board via a 50 conductor ibbon cable.

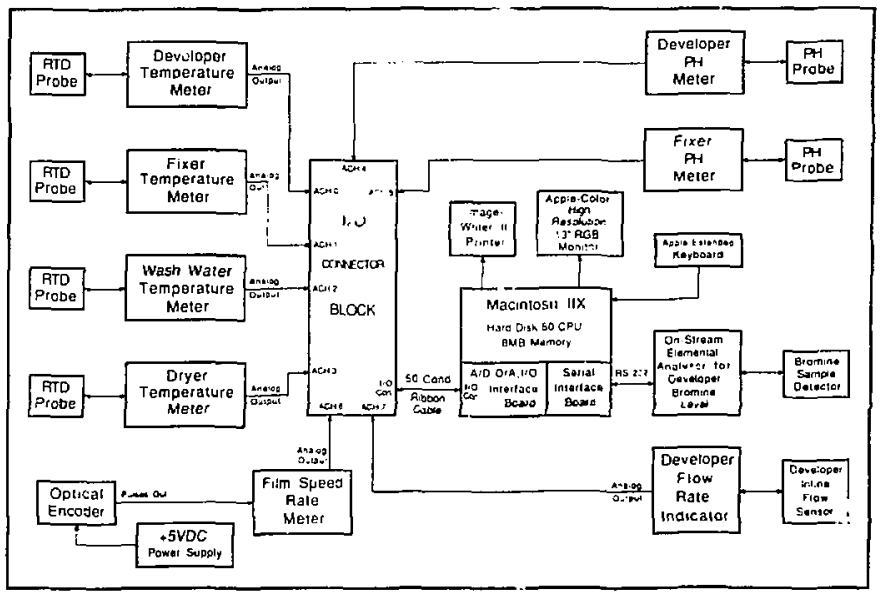

Figure 2. Procsssor monitoring system block diagram. 
An 'n-line $x$-ray nuorescence elemental analyzer has recently been added to the system for measuring bromine concentration (grams per liter) in the developer solution. A serial interface board was installed in the Computer to allow the analyzers data report to be read and then tolerance tested, displayed on the monitor, and stored in a file along with the other eight processor yarjables.

\section{Description of LabViEW 2 Processor Monitoring Program.}

The computer samples the nine processor variables (developer remperature, $\mathrm{pH}$, bromine level, and flow rate; fixer temperature and $\mathrm{pH}$; wash water temperature; dryer temperature; and film iransport sueed) once every tininute. The signals are scaled and converted to engineering units, then tested ior civer and under tolerance leve's and displays on the computer monitor panel (see figure 3). If a processor variable reading is out of tolerance the appropriate LED on monitors front panel will be lit red and the out of tolerance data is written to the ImageWriter II printer and stored in a text file. (Example: 1/30/91 1:51:21 PM DRYER TEIMP. BELOW TOLERANCE 109.4 DEG. F) The Program also stores all processor variable datt in a spread sheet file, which can be plotted on a graph to determine the processors performance over a perjod of ime. $A$ copy of the computer moniton panel can be printed out over the appletalk network to a LaserWriter printer whiie the program is running. This is usually done before and after a batch of fum is developed giving a repored record of processor variables to go with the films.

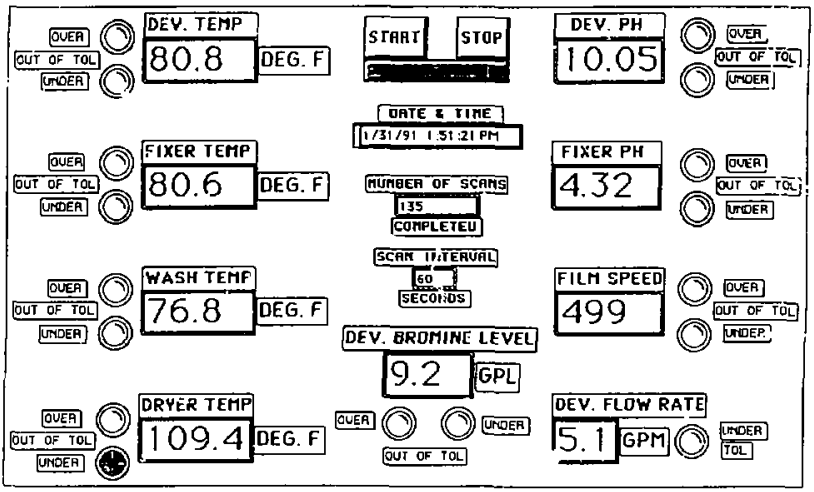

Figure 3. Computer munitor panel. 


\section{Future Ideas and Possibilities}

It is possible to modify the processor monitor system to perform certain control functions, such as; tighter PID control of developer and dryer temperatures, and automation of developer and fixer replenishment as a function of $\mathrm{pH}$ levels and bromine concentration. Another possibility is to install a bar code reader at the output of the dryer section to read UPC bar coded films as they exit the processor. This approach would make it possible to record all the processor variables, along with tach films bar code number, at the time it was processed. Another idea is to trigger a separate data storage routine to occur when a film is detected by the entrance roller switches of the processor. This program routine could time the developer variables to be read and stored while the film is submerged in the devcloper tank, and the fixer variables when the film is traveling through its tank, and so on. This approach, along with a tar code reader, would be the ideal to produce a complete report of processor variables for each film developed. These ideas and possibilities can be achieved with the existing Macintosh based computer system and could be implemented in the future if the need arises.

\section{System Installation}

The plumbing and instrumentation of the replacement (Kodak X-Omat Model B) processor was accomplished by mounting an L-shaped tray within the processor, on the drive side below the developer heater and recirculating pumps, to prevent disturbing the engineered air flow within the processor. In this tray was placed the necessary plumbing for the developer $\mathrm{pH}$ probe, flow sensor head assembly, outlet for the bromine analyzer system and the fixer $\mathrm{pH}$ probe plumbing. Probes to monitor the developer, fis 2 r, and wash warer temperature were mounted to the transport rack support on the non-drive side at the top of the tanks to avoid interfering with removal and replacement of the film transpon racks. The dryer temperature probe was mounted in the upper air plenum outlet adjacent to the existing temperature probe. An optical encoder was also installed on the drive chain above the drive motor to monitor the film transport speed.

\section{Initial Operating Experience}

Since the installation of the processor and computer based monitoring system (but before installation of the bromine analyzer), several instances have arisen to demonstrate the usefulness of the monitoring system. In one case, when mixing new chemicals in the replenishment tank, a valve between the tank and the replenishment purnp was inadvertently left closed. Within hours after the prsiessor was placed back into service the $\mathrm{pH}$ meter began to show a significant drop in $\mathrm{pH}$ levels for that chemical. In another case, after the processor had been shut down for a long weekend it was cleaned and restarted. Then it was noticed that the $\mathrm{pH}$ readings were low. Upon investigation it was noted that the replenishment pumps were not operaing. When the pumps were replaced and the processor restarted, it was discovered that the temperature in the developer tank would not come up to $81^{\prime \prime} \mathrm{F}$ as required. This led us to check the circuit breaker on the thermal chamber which was found to be tripped. These examples illustrate that the monitoring system has been effective in giving early warnir.gs of problems that may exist so corrective action can be taken before film is affected. 


\section{Closure}

To date, the principal benefits of the monitored system have been a real reduction in the cost of maintenance and loss of product and an increase in the availability of the system. The on-line bromine analyzer has recently been installed and calibrated Comparison of the uniformity and reproducibility of precision densitometric films will follow as fully

monitored production increases. We have in addition initiated a development study contract with a major film manufacturer for the purpose of documenting variability in films and processing in precision dosimetry and comparing one-use (gel based) and reusable (automatic processor) development chemistries. 


\section{Why Verify Performance?}

Scjarating $\mathrm{x}$-ray source fluctuations from film processing variations is a difĩcult task. We have established a system which monitors the performance of our film and film jrocessing. In order to monitor consistency we have developed two devices, the "spotburner" and the "flasher". The spotburner allows us to expose uniformi small spots using a $\mathrm{Ca}-109$ source over representative areas of a film. For each production film batch to be processed we use two spotburner films, one leading and one trailing the production films. To identify these films we use the flasher to mark the films with time and date. Production film batch information as well as imporant processor parameters are recorded in a data base for analysis and to keep a historical record.

Quantitative radiography is very sensitive to film and processor variations. These variations may be brought about by many causes. One cause could be variation in the emulsion across the surface of a film. When exposing a film for quantitative analysis a stepwedge of a known material is exposed along with the part to be evaluated. Any emulsion changes from the area $\mathrm{cf}$ the stepwedge to the area of the test piece can make significant errors in perceived $x$-ray atteratation. A second cause of variations are fluctuations in the output of the $x$-ray source or changes in the flight path. A third source of film variations are processor fluctuations. Changes in developer chemistry, developer and rinse water temperatures, and film movement rates through the processor can all cause a shift in apparent exposure from one side of a film to the other.

\section{The Spotburner}

The spotbumer consists of a Cd-109 $\therefore$ ray source, a vacuum platen to : acurely hold a film, and an X-Y positioning system to accurately place the film under the source. A set of $f$ ur exposures, are repeated at nine locations covering the surface of the film. Figure 1 is a digitized image of an entire $7 \times 17$ inch spot bumer film. The exposure times are chosen to produce a set of four film densities which span the useful range of our film digitizer. Figure 2 presents one set of four spots in units of transmitted light. Figure 3 is the same image as Figure 2 with the data converted to film density. As each film is loaded the exposure times are computed to take into account the decay of the $\mathrm{Cd}-109$ source. Since the initial installation the exposure times have increased by over four times with a change in film density of less than 1 percent.

\section{The Flasher}

When 2 batch of films are ready to be processed two spot films are prepured. One precedes the production films through the processor and the second one trails thein. When the :e films are developed it is important that the two spot films are labeled so that the two fil'ms can be identified, as well as marked with pertinent batch irformation.

The flasher was developed to mark the spot films. The flasher uses a plasma discharge display capable of ascii data input and a fresnel lens to focus the image from the plasma display onto the film. The label information, film number and batch number, are loaded into the display through the ascii input. The bare spot film is inserted into a slot on the flasher. A switch is tripped by the film. The label information and the date and time are then exposed on the spot film. 


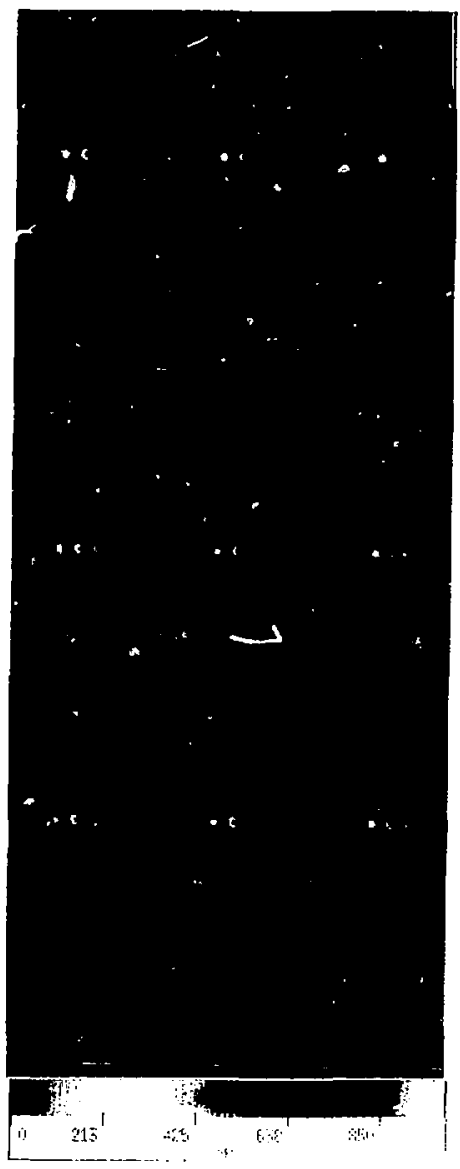

Figure 1 Digitized image of a filnı from the spot burner in units of transmitted light level. 

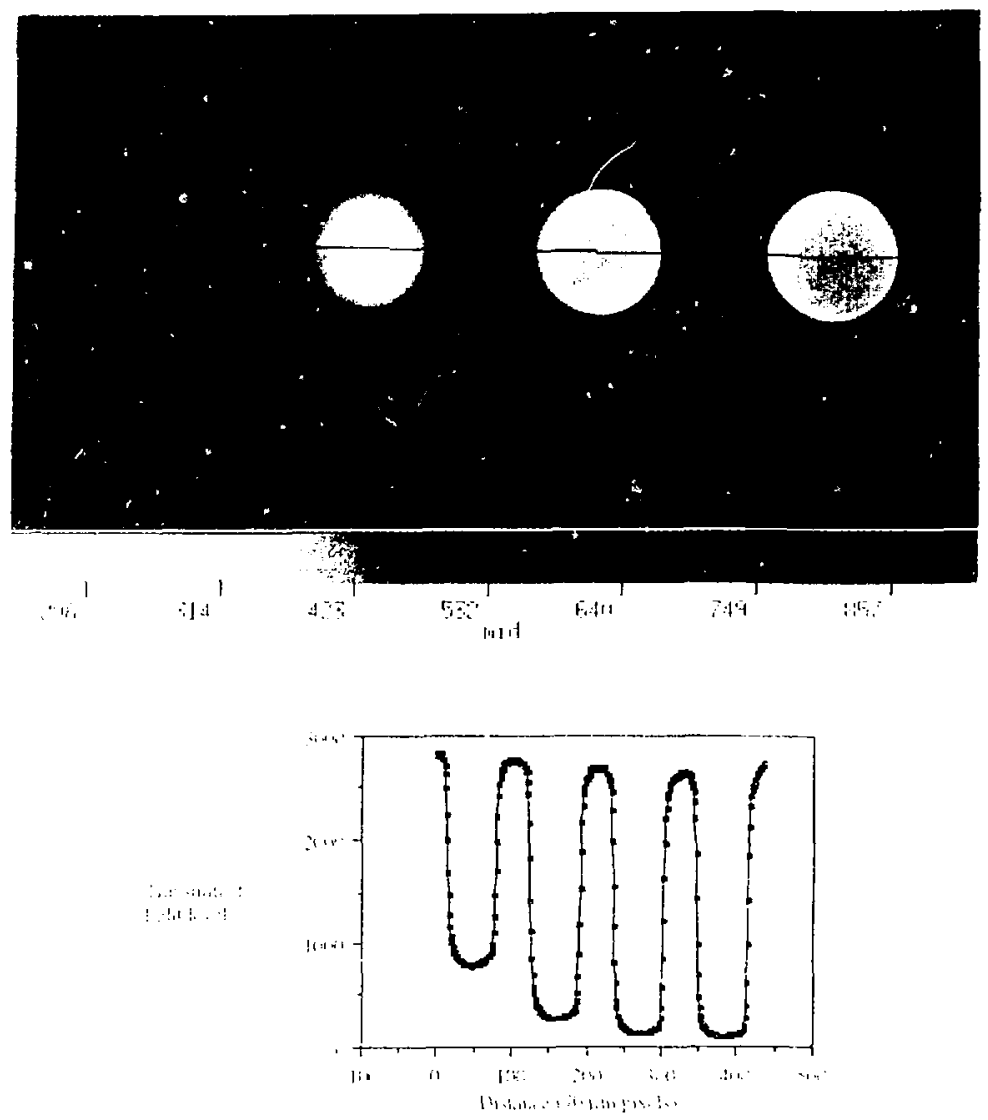

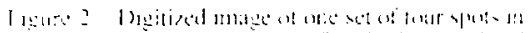

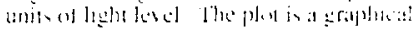

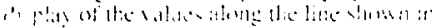
the iminge 

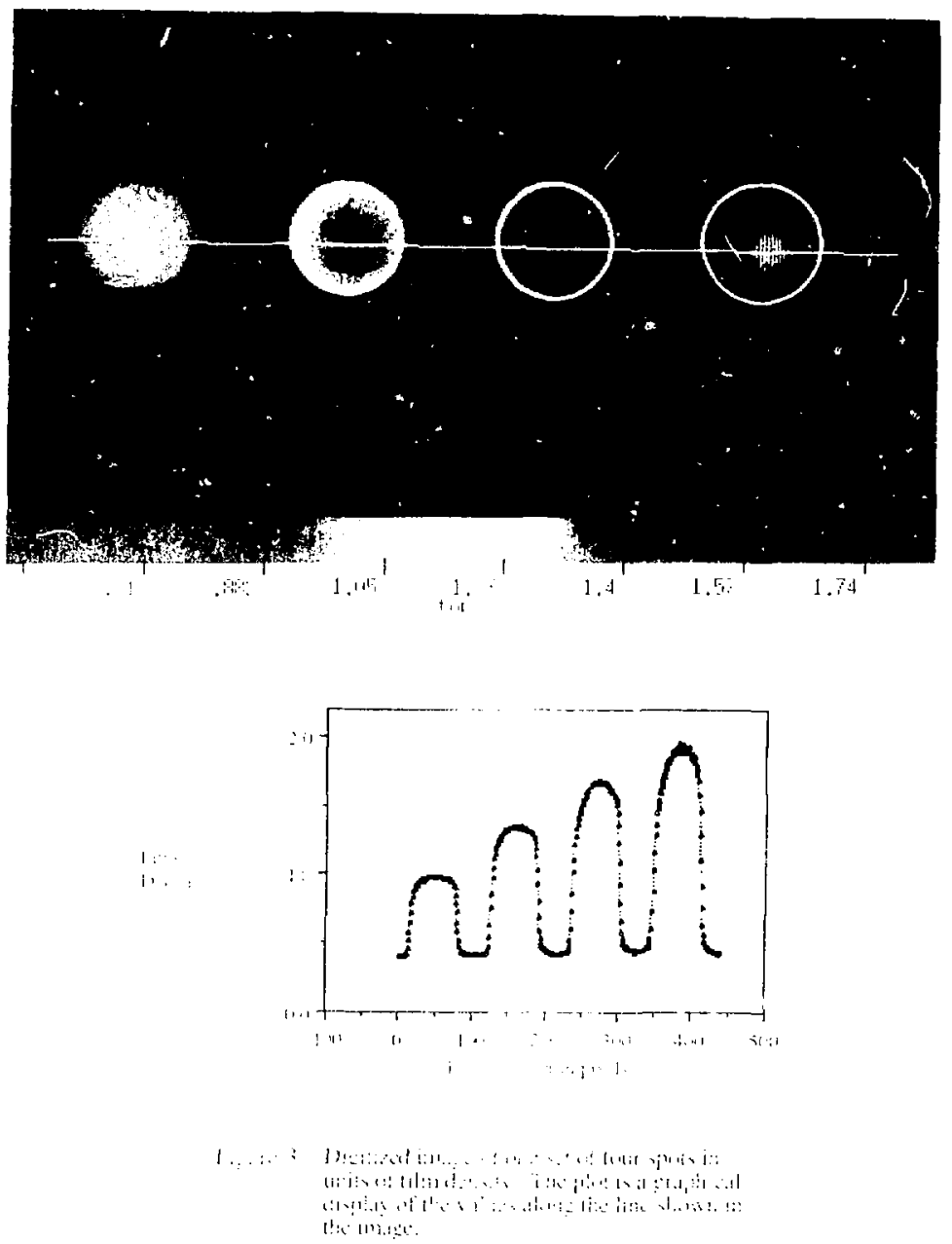


\section{The Data Base}

As each spot film enters the developer a number of important parameters are saved. These parameter values are later entered into a data base. As these values are entered they are checked against a limit range. Any out of range parameters are reported to the operator. A decision can then be made whether or not to repeat the production film exposures.

The spot films are also digitized and the spot film densities are stored in the data base. The spot densities are compared from spot to spot on the same film and also against a set of target densities. Any tolerance erors are reported. The entire system can then be checked for problems.

\section{Summary}

The spotburner, flasher, and the associated data base have proven to be very useful. The system has not only helped in tuning our film processor but has also been used in preparing films for several studies on scatter and exposure. The film provessing monitor system has become a very imponant part of our quantitative radiography system. 


\section{Introduction}

Radiographic images are often distorted by scattered radiation. Radiation can be scattered into the part image by extemal sources or vithin the image by the part material itself. The effect is most pronounced at part edges and is often referred to as undercit. We have corrected digitized film images of simple parts for both types of scatter.

We quantitatively characterize synthetic composite materials using digitized film radiography. Typical parts are simple rectanguiar slabs of uniform thickness between 4 and $7 \mathrm{~mm}$ and generally less than $15 \mathrm{~cm}$ in other dimensions. We digitize the radiographs to make it possible to detect gradients in material density as small as a few percent across a part.

Some materials and radiographic set-up's have large apparent gradients in density near part edges which is caused by scattered radiation. This eftect, often $5 \%$ or more in density can extend 2-3 mm into a part and impair our ability to determine material characteristics near the edge. Two -ources of scattered radiation contribute to this degradation of image quality near the part edge, photons scattered into the part from extemal sources and photons intially incident on the part which are scar'ered out of the image.

\section{Inage Effects from Scattered Radiation}

Figure 1 shows the different paths by which photons can become part of a radiographic image. The information carying part of the image ( $a$ in Figure 1 ) is formed only by the uncollided photons which are transmitted to the film. Since photon illumination over the entire surface of the par is assumed to be uniform, the pixel-to-pixel variation in the number of information-carrying photons depends only on the areal density or photon absorbing ability of the part material above any given pixel.

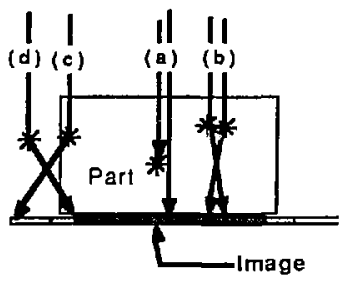

Figure 1. Information bearing photons (a) Internal scatter (b \& c) and extemal scatter (d) 
Photons scattered within the part ( $b$ in Figure 1) end up being "tallied" in pixels other than where the photons were initially directed. In the middle of a large part, the loss of photons scattered out of a pixel is generally compensated by photons scattered from elsewhere into the pixel. The result is a uniform background "noise", (at leist in reasonably uniform parts) reducing contrast, but not markedly changing gradients in the in:age. Near the edge of a part, this trading of scattered photons between pixils becomes non-uniform. $A$ fraction of the photons scattered by part material close to the edge are scattered completely out of the part image ( $c$ in Figure 1). No compensating photons are scattered back into the part image since no part material is present outside the part boundary. The result, if the effect of photons scattered by the part material is considered as an isolated case, is a net loss of photons and thus film density near the edge of the part.

Photons scattered from adjacent objerts are also scattered into the part image $\mathrm{d}$ in Figure 1). Since pixels near the edge of the part are shielded by less par material than pixels in the part center, more of these externally-scattered photons are deposited near the part edge. The result, if the effect of photons scattered external to the part is considered as an isolated case, is a net gain of photons and thus film density near the edge of the part.

In practice, both of the effects described above occur simultaneously. Usually, if no special precautions are taken to mask the part, the number of photons scattered into the image (extemal scatter) is greater than the number scattered out of the i.nage by the par material (internal scatter), causing the film to darken around the edges of the part. This condition is sometimes referred to as "undercut".

\section{Correcting the Image for Scattered Radiation}

The first step of our method consists of making a radiographic image of the external scatter by covering the part with a layer of lead thick enough to biock any radiation incident upon the part (a, b \& $c$ in Figure 1). We use cine representative sample part to provide typical thru-the-part attenuation of the extemal scatter. The result is an image of only the externally-scattered radiation which we call the "bkg. image". A single column trace across the edge of the "bkg image" for a $0.95 \mathrm{~cm}$ thick piece of aluminum bar stock, suspended I/8 inch above the film surface is shown in Figure 2.

Next we construct a computer generated image of the combined transmitted and internallyscattered radiation. We use a Monte Carlo radiation transport code to determine how photons which are scattered within the par distribute themselves into adjacent pixels. This is done by directing photons on a single axis (i.e. only the source photons which would be incident on ose pixel) thru an infinite slab of material of identical thickness and composition to the real par. We tally scattered photon flux in the film plane as a function of distance from the axis of the incident photon beam. We also tally flux which is transmitted uncollided. The uncollided flux into any pixel plus the sum of the scattered flux from all other pixels is the total fux into any pixel from radiation initially incident upon the par itself. 


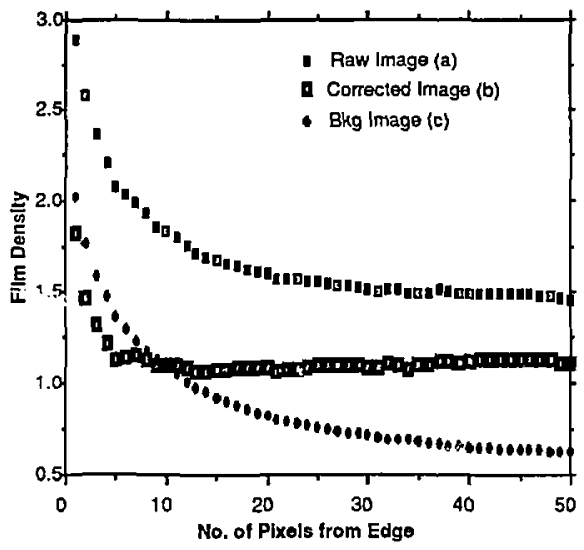

Figure 2. Scans of a single column of pixels across the ecige of the image for a $0.95 \mathrm{~cm}$ thick suspended aluminum bar. The corrected image (b) represents the "signal" portion of the radiograph. The reason for the poor correction to the first four pixels may result form penumbral effects, slight offset in the edge detection, incorrect "Film Density vs Exposure" calibration, slight misalignment of the lead shield used to produce the "bkg". Image or cross-pixel leakage in high gradient regions during digitizing. Each pixel is 70 microns square.

The calculated distribution of scattered photon flux for a suspended $0.95 \mathrm{~cm}$ thick piece of aluminum is shown in Figure 3. This is converted to an image of the internally-scattered radiation by summing for each pixel the scattered radiation contributed by every other pixel. Pixels at the edge of an image are on the average farther from all of the other pixels and thus get less scattered radiation than pixels in the center of the image.

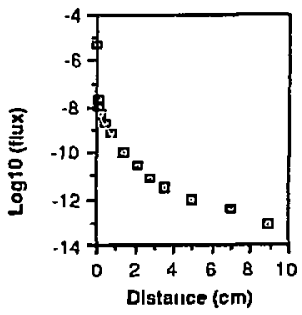

Figure 3. Internal-scatter radiation distribution for the aluminum bar shown in Figure 2. 
To this scattered radiation image we add the uncollided flux, obtained from the same Monte Carlo calculation (this is the same for all pixels and is just the flux of photons which is transmitted thru the material without scattering or being absorbed). The resulting image is normalized by dividing the resulting photon flux in each pixel by the photon flux in the center pixel. This prodices an image in which the sum of the transmitted and intemallyscattered radiation in each pixel is defined as a fraction of that in the center pixel. We call this the "intemal radiation image".

\section{Producing the Corrected Image}

To produce the scatter-corrected iniage of a part, we first subtract each pixel of the "bkg image" from its corresponding pixel in the raw image to eliminate the external scatter contribution. Since the film density vs exposure relationship is not linear, we convert both the par pixel and the "bkg" pixel to units of exposure before subtracting. Figure 4 shows the film density for DuPont NDT-55 as a function of exposure. The result is then divided by the value of the corresponding pixel in the "internal radiation image" to correct for the calculated non-uniformity of internally-scattered radiation. The "internal radiation image" is already in units of relative exposure since we tallied the results of the Monte Carlo calculation in flux. At this point the corrected part image is converted back to film density using Figure 4 and finally to material areal density as described earlier in this report.

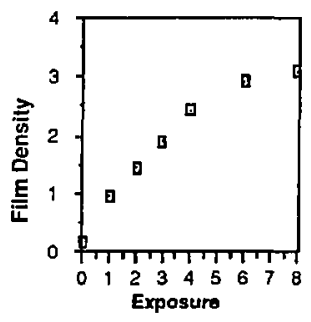

Figure 4. Measured Film Density vs Exposure for DuPont NDT-55 film. One unit of exposure is equal to $2.4 \mathrm{e} 7$ photons/sq-mm of $\mathrm{Cd} 109$ x-rays incident on the film.

Doing the above pixel-by-pixel subtraction and division requires all three images to have the same number of pixels, arrayed in rows and columns of the same length. In practice this is rarely the case as parts are sometimes of slightly different dimensions, warped or chipped. The process of mapping the "bkg and internal radiation images" to overlay the raw image begins with identifying which pixels lie within the part.

To identify the boundaries of the part we plot the film density against the number of pixels with that film density as shown in Figure 5, often called a histogram plot. Two distinct groupings of pixels emerge, those within the part and those that form the dark border around the part. The part edge is defined using a column-by-column search of pixel film densities which starts from a point clearly outside the part in all direction" When 5 
consecutive pixels, having film densities within a defined portion of the part peak are encountered, a part edge for that column is defined. Working from each end of the part, the number of pixels in each column of the "bkg and internal radiation images" is forced to match the raw image by adding or removing center pixels as required (column equalization). Columns of pixels are then added to or removed from the part center to force the number of columns in the "bkg and internal radiation images" to match the raw image (row equalization). The film density of the added pixels is set to the average of the adjacent pixels. Center pixels are selected to be added or removed sirce there is usually little film density gradient along a row or column near its center, while the end region detail is preserved. Each pixel in the "bkg and internal radiation images" now has a corresponding pixel in the raw image, while minor shape variations in the part are preserved.

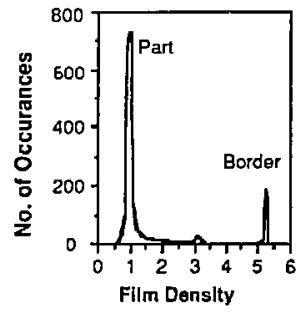

Figure 5. Pixel histogram for Figure 2b. Defined peak width for edge detection is typically two standard deviations but can be varied to change sensitivity.

\section{An Example Image}

To illustrate the improvement on an full image under typical radiographic conditions, we applied this correction procedure to the radiograph of a $0.95 \mathrm{~cm}$ thick aluminum bar. For this example, the image of the bar was acquired with the bar resting on the film. The digitized image is presented in Figure 6 . Underculting is clearly evident. Figure 7 presents the "bkg" image obtained by shielding the area of the aluminum bar and acquiring only the image of radiation scattered into the part image. . Figure 8 presents the calculated internal radiation image and Figure 9 the final result after correction for scatter effects. 


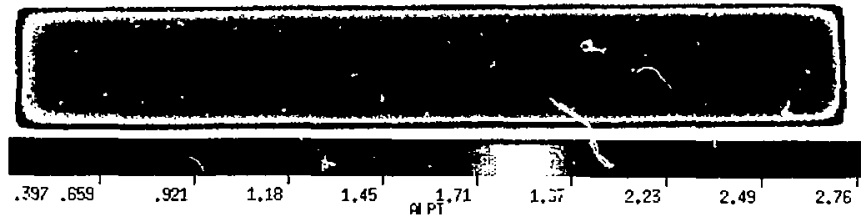

Figure 6. Uncorrected digitized radiograph of $0.95 \mathrm{~cm}$ thick aluminum by showing undercutting.

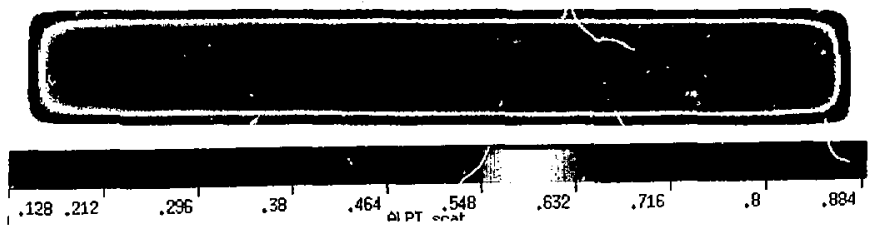

Figure 7. Bkg image of aluminum bar from Figure 6. .

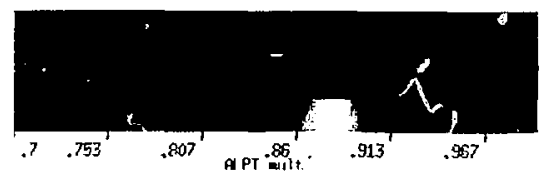

Figure 8. Calculated internal radiation image of the aluminum bar of Figure 6.

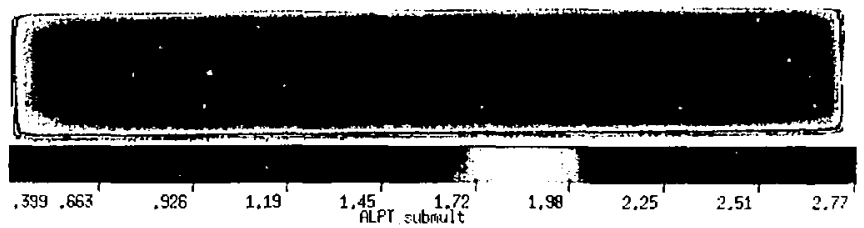

Figure 9. Fully corrected image of aluminum bar of Figure 6. 


\section{Conclusions}

This method provides quantitative first order correction in many simple radiographic images where scatter is a problem. Second order effects such as scatter variation caused by differences between similar parts cannot be corrected and the method is limited to simple geometries generally of uniform thickness due to the large amounts of computer time required to do both the Monte Carlo calculations and produce the "internal radiation image". In many practical cases intemal scatter is not significant relative to extemal and both of these problems are less significant. The film density vs exposure curve we generated using a $\mathrm{Cd}^{109}$ radioactive source is an approximation since the radiographs were produced using a tube spectum. An exact curve would be very difficult to generate due to beam hardening effects. High levels of "bkg" radjation at part edges can cause pixeis at the edge of the image to be discarded as border pixels. When this happens, interior pixels with much lower film densities are interpreted as part edges and subtracted from the edge pixels of the raw image, causing severe under-correction. 
1. E.J. M:Kinney, Ed., "Nondestructive Testing Handboak", Volume 3 ("Radiography and Radiation Testing"), Section 7("Radiographic Latent Image Processing" ), American Society for Nondestructive Testing, New York, 1985.

2. E.J. McKinney, "Rromide Dependence in NDT Radiographic Processing", Proceedings of ASNT Fall Convention, Anaheim, CA, August, 1988. 